\title{
Outcomes in adult congenital heart surgery: Analysis of the Society of Thoracic Surgeons Database
}

\author{
Christopher E. Mascio, MD, ${ }^{\mathrm{a}}$ Sara K. Pasquali, MD, ${ }^{\mathrm{b}}$ Jeffrey P. Jacobs, MD, ${ }^{\mathrm{c}}$ Marshall L. Jacobs, MD, ${ }^{\mathrm{d}}$ and \\ Erle H. Austin III, MD ${ }^{\mathrm{a}}$
}

\begin{abstract}
Objective: Outcomes data for adults undergoing congenital heart surgery are limited. Previous analyses used administrative data or focused on single-center outcomes. We describe the most common operations, patient characteristics, and postoperative outcomes using a multicenter clinical database.
\end{abstract}

\begin{abstract}
Methods: The study included adults (aged $\geq 18$ years) listed in the Society of Thoracic Surgeons Congenital Heart Surgery Database (2000-2009). We describe patient characteristics and morbidity and mortality, and examine congenital procedures in the Society of Thoracic Surgeons Adult Cardiac Surgery Database to permit consideration of the primary dataset within a broader context.
\end{abstract}

Results: A total of 5265 patients (68 centers) from the Society of Thoracic Surgeons Congenital Heart Surgery Database were included. Patients' median age was 25 years (interquartile range, 20-35). Common preoperative risk factors included noncardiac abnormalities (17\%) and arrhythmia (14\%). Overall, in-hospital mortality was $2.1 \%, 27 \%$ had 1 or more complication, and median length of stay was 5 days. Common operations included right ventricular outflow tract procedures $(21 \%)$ and pacemaker/arrhythmia procedures $(20 \%)$. We further evaluated cardiopulmonary bypass procedures in more than 100 patients. Mortality ranged from $0 \%$ (atrial septal defect repair) to $11 \%$ (Fontan revision/conversion). Separate evaluation of the Society of Thoracic Surgeons Adult Cardiac Surgery Database revealed 39,872 adults undergoing congenital heart operations.

Conclusions: Most adult congenital heart operations listed in the Society of Thoracic Surgeons Congenital Heart Surgery Database are performed in the third to fourth decades of life; approximately half are for right heart pathology or arrhythmia. Many patients have complications, but mortality is low with the exception of those undergoing Fontan revision/conversion. Many more adults undergoing congenital heart surgery are entered into the Society of Thoracic Surgeons Adult Cardiac Surgery Database. (J Thorac Cardiovasc Surg 2011;142:1090-7)

Recent estimates of the US population of adults with congenital heart disease (CHD) range from 1 to 3 million. ${ }^{1}$ Only recently have these estimates exceeded those of pediatric patients with congenital heart disease. ${ }^{2-4}$ There are many reasons for emergence of this population. As surgical techniques have improved, survival after even the

From the Division of Thoracic and Cardiovascular Surgery, ${ }^{\mathrm{a}}$ Department of Surgery, University of Louisville, Louisville, Ky; Division of Cardiology, ${ }^{\mathrm{b}}$ Department of Pediatrics, Duke University Medical Center, and Duke Clinical Research Institute, Durham, NC; Division of Thoracic and Cardiovascular Surgery, ${ }^{\mathrm{c}}$ The Congenital Heart Institute of Florida, All Children's Hospital, University of South Florida College of Medicine, Saint Petersburg and Tampa, Fla; and Department of Pediatric and Congenital Heart Surgery, ${ }^{\mathrm{d}}$ Center for Pediatric and Congenital Heart Diseases, Cleveland Clinic Foundation, Cleveland, Ohio.

Funding: S.K.P. received grant support (1K08HL103631-01) from the National Heart, Lung, and Blood Institute, and the American Heart Association Mid-Atlantic Affiliate Clinical Research Program. J.P.J. is Chair, Society of Thoracic Surgeons Congenital Heart Surgery Database Task Force.

Disclosures: Authors have nothing to disclose with regard to commercial support.

Read at the 91st Annual Meeting of The American Association for Thoracic Surgery, Philadelphia, Pennsylvania, May 7-11, 2011.

Received for publication May 5, 2011; revisions received July 11, 2011; accepted for publication July 19, 2011; available ahead of print Sept 12, 2011.

Address for reprints: Christopher E. Mascio, MD, 201 Abraham Flexner Way-Suite 1200, Louisville, KY 40202 (E-mail: cmascio@ louisvilleheartsurgery.com).

0022-5223/\$36.00

Copyright (c) 2011 by The American Association for Thoracic Surgery

doi:10.1016/j.jtcvs.2011.07.028 most complex operations has dramatically improved over the past 2 decades. ${ }^{5}$ Advancements in supportive disciplines, including intensive care, have coincided with these operative improvements. ${ }^{2,6}$ Although most infants and children who undergo operations for congenital heart disease survive, the surgery rarely offers a definitive cure. With the exception of atrial septal defect (ASD) repair, the life expectancy of those born with congenital heart disease is lower than of the general population. ${ }^{7}$ For many congenital cardiac lesions, the generation of patients currently reaching adulthood represents the first sizeable group to have done so, and the late problems associated with surgically treated congenital heart disease are becoming increasingly apparent. Reports published to date have generally focused on individual lesions or on one aspect of caring for adults with CHD, and the majority report single institution experiences. ${ }^{8-10}$ Of multi-institutional reports, many rely on administrative data. ${ }^{11}$ There are a paucity of reliable data available for use in counseling patients, families, and other clinicians with respect to mortality and expected complications for adults with CHD undergoing cardiac surgery. The Society of Thoracic Surgeons (STS) Congenital Heart Surgery Database collects perioperative information on all patients at participating institutions undergoing operations 

Abbreviations and Acronyms
ASD $=$ atrial septal defect
$\mathrm{CHD}=$ congenital heart disease
$\mathrm{CPB}=$ cardiopulmonary bypass
$\mathrm{IQR}=$ interquartile range
STS $=$ Society of Thoracic Surgeons

for congenital heart disease. Approximately three quarters of all centers performing congenital heart surgery submit data to this database, and therefore it is a potentially valuable repository of surgical information on adults with CHD. ${ }^{12}$ The primary objective of this study was to describe the patient characteristics, most common operations, and operative morbidity and mortality of patients aged 18 years or more undergoing surgery for congenital heart disease, by using the STS Congenital Heart Surgery Database. Information concerning patients undergoing surgery for congenital heart disease that is collected in the STS Adult Cardiac Surgery Database is considerably less detailed than that collected in the STS Congenital Heart Surgery Database. Nonetheless, we also sought to determine the overall number of CHD operations that have been entered in the adult database during the same period of time to permit consideration of the primary dataset within a broader context.

\section{MATERIALS AND METHODS \\ Data Source}

The STS Congenital Heart Surgery Database contains operative, perioperative, and outcomes data on more than 180,000 patients undergoing congenital heart surgery since 1998. Data on all patients undergoing congenital heart surgery at participating centers are entered into the database. Data quality and reliability are ensured through intrinsic verification of data and a formal process of site visits and data audits. ${ }^{13}$

In addition, we identified congenital procedures entered into the STS Adult Cardiac Surgery Database. Although the adult database currently captures more limited data regarding congenital heart operations, this information provides an estimate of the number of CHD operations performed at adult hospitals or by adult cardiac surgeons.

The Duke Clinical Research Institute serves as the data warehouse and analytic center for all of the STS National Databases. This analysis was approved by the Duke Institutional Review Board and by the STS Access and Publications Committee.

\section{Patient Population}

Analysis of data from the STS Congenital Heart Surgery Database was restricted to 68 centers with more than $85 \%$ complete data for all study variables. Although the STS Database contains nearly complete data for the standard core data fields required to calculate in-hospital mortality, not all centers submit complete data for all variables, such as patient preoperative characteristics or postoperative complications. Therefore, it is standard practice to exclude centers with more than $15 \%$ missing data for key study variables to maximize data integrity and minimize missing data. ${ }^{14}$ From the included centers, patients aged 18 years or more who underwent any congenital heart operation between 2000 and 2009 were included.

Similar criteria were applied to the STS Adult Cardiac Surgery Database. The only congenital operations captured in the adult database during this time period included ASD repair, pulmonary valve replacement, and "congenital defect repair."

\section{Data Collection}

Data collected from the STS Congenital Heart Surgery Database included demographic information, cardiac diagnoses, presence of noncardiac/genetic abnormality, and presence of any other preoperative factors as defined in the database, including mechanical circulatory support, acidosis, shock, arrhythmia, atrioventricular block, pulmonary hypertension, mechanical ventilatory support, tracheostomy, renal failure (creatinine > 2), renal failure requiring dialysis, bleeding disorder, endocarditis, sepsis, neurologic deficit, or seizure. ${ }^{15}$ Operative data included the surgical procedure performed, which was analyzed individually and categorized using the STS-European Association for Cardiothoracic Surgery risk stratification system (category $1=$ lowest mortality risk, category $5=$ highest mortality risk). ${ }^{16}$ This system was recently developed on the basis of empiric data from approximately 80,000 patients, and it includes a greater number of operations compared with other risk stratification systems. ${ }^{16}$ The number of prior cardiothoracic operations was also collected, as well as cardiopulmonary bypass (CPB) times. Outcomes data included in-hospital mortality, total postoperative length of stay, and postoperative complications, including cardiovascular, pulmonary, neurologic, renal, infectious, and hematologic complications, as well as the need for unplanned surgical reintervention during the hospitalization, as defined in the STS Database. ${ }^{15}$

Data collection from the STS Adult Cardiac Surgery Database was limited to the procedure performed (as captured in this database), demographics, and in-hospital mortality. Procedures in the adult database were categorized as isolated procedures or concomitant procedures in association with coronary artery bypass grafting, aortic valve procedure, or mitral valve procedure.

\section{Analysis}

Study variables were described using standard summary statistics. Preoperative, operative, and outcomes data were described for the overall cohort and for subgroups of patients undergoing the most common operations. Because of the descriptive nature of the analysis, formal statistical comparisons were not made. All analyses were performed using SAS version 9.2 (SAS Institute Inc, Cary, NC).

\section{RESULTS}

\section{Society of Thoracic Surgeons Congenital Heart} Surgery Database

Patient characteristics and overall outcomes. A total of 5265 patients from 68 centers submitting data to the STS Congenital Heart Surgery Database were included in the primary analysis. Patient characteristics are shown in Table 1. Patients' median age was 25 years (interquartile range [IQR], 20-35). The most common preoperative risk factors were the presence of any noncardiac/genetic abnormality $(17 \%)$ and preoperative arrhythmia $(14 \%)$. The most common categories of operations were right ventricular outflow tract/pulmonary artery procedure $(21 \%$ of all operations, including pulmonary valve replacement or repair, conduit operation, and pulmonary artery reconstruction), pacemaker/arrhythmia procedure $(20 \%$, including pacemaker or defibrillator implantation/procedure, and atrial or ventricular arrhythmia surgery), left ventricular outflow tract/aortic valve procedure $(18 \%$, including subaortic stenosis repair, aortic valve replacement or repair, 
TABLE 1. Study population characteristics

\begin{tabular}{|c|c|c|c|c|c|c|c|c|}
\hline & $\begin{array}{c}\text { Overall } \\
(n=5265)\end{array}$ & $\begin{array}{l}\text { Pulmonary } \\
\text { valve } \\
\text { replacement } \\
(\mathbf{n}=\mathbf{5 7 4})\end{array}$ & $\begin{array}{l}\text { ASD repair } \\
(\mathbf{n}=\mathbf{3 6 5})\end{array}$ & $\begin{array}{l}\text { Conduit } \\
\text { operation } \\
(n=328)\end{array}$ & $\begin{array}{c}\text { Aortic } \\
\text { aneurysm } \\
\text { repair } \\
(\mathbf{n}=136)\end{array}$ & $\begin{array}{c}\text { Mitral } \\
\text { valvuloplasty } \\
(\mathbf{n}=\mathbf{1 3 5})\end{array}$ & $\begin{array}{c}\text { Ross } \\
\text { operation } \\
(\mathbf{n}=\mathbf{1 0 8})\end{array}$ & $\begin{array}{c}\text { Fontan } \\
\text { revision/ } \\
\text { conversion } \\
(\mathbf{n}=\mathbf{1 0 5})\end{array}$ \\
\hline Age (y) & $25[20-35]$ & $25[20-35]$ & $33[23-46]$ & 23 [20-29] & $24[21-31]$ & $26[20-37]$ & 22 [19-28] & $27[22-33]$ \\
\hline Weight $(\mathrm{kg})$ & $69[58-83]$ & $70[59-86]$ & $71[59-84]$ & $67[55-79]$ & $78[62-89]$ & $66[53-76]$ & $73[63-83]$ & $68[56-79]$ \\
\hline Race, white & $3872(74 \%)$ & $439(76 \%)$ & $242(66 \%)$ & $262(80 \%)$ & $112(82 \%)$ & $96(71 \%)$ & $91(84 \%)$ & $84(80 \%)$ \\
\hline Sex, male & $2631(50 \%)$ & $277(48 \%)$ & $131(36 \%)$ & $178(54 \%)$ & $90(66 \%)$ & $38(28 \%)$ & $75(69 \%)$ & $51(49 \%)$ \\
\hline Noncardiac abnormality & $899(17 \%)$ & $84(15 \%)$ & $25(6.9 \%)$ & $52(16 \%)$ & $32(24 \%)$ & $37(27 \%)$ & $7(6.5 \%)$ & $11(10 \%)$ \\
\hline \multicolumn{9}{|l|}{ Preoperative factors } \\
\hline Any & $1655(31 \%)$ & $106(18 \%)$ & $63(17 \%)$ & $92(28 \%)$ & $25(18 \%)$ & $42(31 \%)$ & $15(14 \%)$ & $71(68 \%)$ \\
\hline Arrhythmia & $735(14 \%)$ & $36(6.3 \%)$ & $20(5.5 \%)$ & $25(7.6 \%)$ & $4(2.9 \%)$ & $16(12 \%)$ & $1(0.9 \%)$ & $56(53 \%)$ \\
\hline AV block & $144(2.7 \%)$ & $1(0.2 \%)$ & $1(0.3 \%)$ & $5(1.5 \%)$ & $1(0.7 \%)$ & $2(1.5 \%)$ & $1(0.9 \%)$ & $1(1.0 \%)$ \\
\hline Mechanical ventilation & $89(1.7 \%)$ & $1(0.2 \%)$ & $0(0 \%)$ & $3(0.9 \%)$ & $2(1.5 \%)$ & $1(0.7 \%)$ & $0(0 \%)$ & $0(0 \%)$ \\
\hline Pulmonary hypertension & $65(1.2 \%)$ & $3(0.5 \%)$ & $4(1.1 \%)$ & $6(1.8 \%)$ & $0(0 \%)$ & $3(2.2 \%)$ & $0(0 \%)$ & $1(1.0 \%)$ \\
\hline Neurologic deficit & $177(3.4 \%)$ & $12(2.1 \%)$ & $8(2.2 \%)$ & $13(4.0 \%)$ & $3(2.2 \%)$ & $4(3.0 \%)$ & $3(2.8 \%)$ & $3(2.9 \%)$ \\
\hline Seizure & $61(1.2 \%)$ & $6(1.1 \%)$ & $1(0.3 \%)$ & $6(1.8 \%)$ & $3(2.2 \%)$ & $2(1.5 \%)$ & $0(0 \%)$ & $0(0 \%)$ \\
\hline Endocarditis & $73(1.4 \%)$ & $0(0 \%)$ & $1(0.3 \%)$ & $9(2.7 \%)$ & $4(2.9 \%)$ & $4(3.0 \%)$ & $3(2.8 \%)$ & $0(0 \%)$ \\
\hline Bleeding disorder & $68(1.3 \%)$ & $8(1.4 \%)$ & $3(0.8 \%)$ & $8(2.4 \%)$ & $2(1.5 \%)$ & $2(1.5 \%)$ & $4(3.7 \%)$ & $3(2.9 \%)$ \\
\hline
\end{tabular}

Continuous variables are presented as median [IQR]. Preoperative factors occurring in more than $1 \%$ of the overall study population are shown. ASD, Atrial septal defect; $A V$, atrioventricular.

aortic root replacement of any type, aortic aneurysm repair, Ross procedure, and Ross-Konno procedure), ASD closure $(7 \%)$, mitral valve repair or replacement $(5 \%)$, and Fontan operation ( $4 \%$, any type). In-hospital mortality for the overall cohort was $2.1 \%, 27 \%$ had 1 or more postoperative complications, and median postoperative length of stay was 5 days (IQR 3-7).

Patient characteristics and outcomes associated with the most common adult congenital heart disease operations. All individual operations involving CPB with more than 100 patients were evaluated further; this included pulmonary valve replacement, ASD repair, right ventricle to pulmonary artery conduit operation, aortic aneurysm repair, mitral valvuloplasty, Ross operation, and Fontan revision/conversion. Tables 1 to 3 list the population characteristics, operative characteristics, and outcomes for these 7 operations. Pulmonary valve replacement was the most common operation. In-hospital mortality for this operation was low $(0.7 \%)$, and median length of stay was 5 days (IQR, 4-6). Patients with ASD were relatively old at the time of operation compared with patients undergoing other operations (median, 33 years; IQR, 23-46). As expected, they had a short CPB time (median, 61 minutes; IQR, 43-87). Patients with ASD had a mortality of $0 \%$ and a short length of stay (median, 4 days; IQR, 3-5). The conduit operation cohort was notable for having a rate of preoperative neurologic deficit of $4.0 \%$. In addition, this group had a high number of previous cardiothoracic operations (median, 2; IQR, 1-3). The conduit operation cohort also had a relatively high rate of postoperative pulmonary complications (pleural effusion, reintubation, and mechanical ventilation $>7$ days). The aortic aneurysm repair subgroup was notable for having

TABLE 2. Operative characteristics

\begin{tabular}{|c|c|c|c|c|c|c|c|c|}
\hline & $\begin{array}{c}\text { Overall } \\
(\mathrm{n}=\mathbf{5 2 6 5})\end{array}$ & $\begin{array}{c}\text { Pulmonary } \\
\text { valve replacement } \\
(\mathrm{n}=\mathbf{5 7 4}) \\
\end{array}$ & $\begin{array}{c}\text { ASD } \\
\text { repair } \\
(\mathbf{n}=\mathbf{3 6 5}) \\
\end{array}$ & $\begin{array}{c}\text { Conduit } \\
\text { operation } \\
(\mathbf{n}=\mathbf{3 2 8}) \\
\end{array}$ & $\begin{array}{c}\text { Aortic } \\
\text { aneurysm } \\
\text { repair }(\mathbf{n}=\mathbf{1 3 6}) \\
\end{array}$ & $\begin{array}{c}\text { Mitral } \\
\text { valvuloplasty } \\
(\mathbf{n}=\mathbf{1 3 5}) \\
\end{array}$ & $\begin{array}{c}\text { Ross } \\
\text { operation } \\
(\mathbf{n}=\mathbf{1 0 8}) \\
\end{array}$ & $\begin{array}{c}\text { Fontan revision/ } \\
\text { conversion } \\
(\mathbf{n}=\mathbf{1 0 5}) \\
\end{array}$ \\
\hline \multicolumn{9}{|l|}{ STS-EACTS category } \\
\hline 1 & $2051(39 \%)$ & - & - & - & - & - & - & - \\
\hline 2 & $1793(34 \%)$ & & & & & & & \\
\hline 3 & $396(7.5 \%)$ & & & & & & & \\
\hline 4 & $675(13 \%)$ & & & & & & & \\
\hline 5 & $6(0.1 \%)$ & & & & & & & \\
\hline $\begin{array}{l}\text { No. of prior cardiothoracic } \\
\text { operations }\end{array}$ & $1[0-2]$ & $1[1-2]$ & $0[0-0]$ & $2[1-3]$ & $1[0-2]$ & $0[0-1]$ & $0[0-1]$ & $2[2-3]$ \\
\hline CPB time (min) & 117 [78-175] & $91[66-121]$ & 61 [43-87] & 09 [75-165] & ] 172 [120-222] & $120[92-177] 1$ & 95 [164-237] & 195 [153-250] \\
\hline
\end{tabular}

Continuous variables are presented as median [IQR]. ASD, Atrial septal defect; STS, Society of Thoracic Surgeons; EACTS, European Association for Cardiothoracic Surgery. 


\begin{tabular}{|c|c|c|c|c|c|c|c|c|}
\hline & $\begin{array}{c}\text { Overall } \\
(\mathrm{n}=\mathbf{5 2 6 5})\end{array}$ & $\begin{array}{l}\text { Pulmonary } \\
\text { valve } \\
\text { replacement } \\
(n=574)\end{array}$ & $\begin{array}{c}\text { ASD } \\
\text { repair } \\
(\mathbf{n}=\mathbf{3 6 5})\end{array}$ & $\begin{array}{c}\text { Conduit } \\
\text { operation } \\
(\mathbf{n}=\mathbf{3 2 8})\end{array}$ & $\begin{array}{c}\text { Aortic } \\
\text { aneurysm } \\
\text { repair } \\
(\mathbf{n}=136)\end{array}$ & $\begin{array}{c}\text { Mitral } \\
\text { valvuloplasty } \\
(\mathbf{n}=\mathbf{1 3 5})\end{array}$ & $\begin{array}{c}\text { Ross } \\
\text { operation } \\
(\mathbf{n}=\mathbf{1 0 8})\end{array}$ & $\begin{array}{c}\text { Fontan } \\
\text { revision/ } \\
\text { conversion } \\
(\mathbf{n}=\mathbf{1 0 5})\end{array}$ \\
\hline In-hospital mortality & $109(2.1 \%)$ & $4(0.7 \%)$ & $0(0 \%)$ & $8(2.4 \%)$ & $3(2.2 \%)$ & $1(0.7 \%)$ & $2(1.9 \%)$ & $11(11 \%)$ \\
\hline Length of stay (d) & $5[3-7]$ & $5[4-6]$ & $4[3-5]$ & $5[4-7]$ & $6[4-8]$ & $5[4-8]$ & $5[4-6]$ & $10[7-13]$ \\
\hline \multicolumn{9}{|l|}{ Postoperative complication } \\
\hline Any & $1446(28 \%)$ & $135(24 \%)$ & $72(20 \%)$ & $96(29 \%)$ & $35(26 \%)$ & $48(36 \%)$ & $43(40 \%)$ & $54(51 \%)$ \\
\hline Arrhythmia & $496(9.4 \%)$ & $39(6.8 \%)$ & $28(7.7 \%)$ & $26(7.9 \%)$ & $8(5.9 \%)$ & $22(16 \%)$ & $11(10 \%)$ & $24(23 \%)$ \\
\hline Low cardiac output & $87(1.7 \%)$ & $4(0.7 \%)$ & $3(0.8 \%)$ & $5(1.5 \%)$ & $2(1.5 \%)$ & $4(3.0 \%)$ & $4(3.7 \%)$ & $9(8.6 \%)$ \\
\hline $\begin{array}{l}\text { AV block requiring } \\
\text { permanent pacer }\end{array}$ & $69(1.3 \%)$ & $0(0 \%)$ & $0(0 \%)$ & $1(0.3 \%)$ & $3(2.2 \%)$ & $1(0.7 \%)$ & $2(1.9 \%)$ & $1(1.0 \%)$ \\
\hline Cardiac arrest & $52(1.0 \%)$ & $2(0.4 \%)$ & $0(0 \%)$ & $7(2.1 \%)$ & $3(2.2 \%)$ & $1(0.7 \%)$ & $0(0 \%)$ & $3(2.9 \%)$ \\
\hline Pleural effusion & $162(3.1 \%)$ & $6(1.1 \%)$ & $6(1.6 \%)$ & $12(3.7 \%)$ & $4(2.9 \%)$ & $11(8.2 \%)$ & $4(3.7 \%)$ & $7(6.7 \%)$ \\
\hline Pneumonia & $124(2.4 \%)$ & $19(3.3 \%)$ & $12(3.3 \%)$ & $3(0.9 \%)$ & $0(0 \%)$ & $0(0 \%)$ & $0(0 \%)$ & $1(1.0 \%)$ \\
\hline Reintubation & $71(1.4 \%)$ & $1(0.2 \%)$ & $1(0.3 \%)$ & $8(2.4 \%)$ & $1(0.7 \%)$ & $2(1.5 \%)$ & $1(0.9 \%)$ & $6(5.7 \%)$ \\
\hline Mechanical ventilation $>7 \mathrm{~d}$ & $52(1.0 \%)$ & $0(0 \%)$ & $2(0.6 \%)$ & $7(2.1 \%)$ & $1(0.7 \%)$ & $0(0 \%)$ & $0(0 \%)$ & $6(5.7 \%)$ \\
\hline Unplanned reoperation & $111(2.1 \%)$ & $4(0.7 \%)$ & $2(0.6 \%)$ & $6(1.8 \%)$ & $4(2.9 \%)$ & $3(2.2 \%)$ & $1(0.9 \%)$ & $5(4.8 \%)$ \\
\hline $\begin{array}{l}\text { Bleeding requiring } \\
\text { reoperation }\end{array}$ & $100(1.9 \%)$ & $7(1.2 \%)$ & $2(0.6 \%)$ & $6(1.8 \%)$ & $4(2.9 \%)$ & $1(0.7 \%)$ & $9(8.3 \%)$ & $4(3.8 \%)$ \\
\hline $\begin{array}{c}\text { Renal failure requiring } \\
\text { temporary dialysis }\end{array}$ & $56(1.1 \%)$ & $3(0.5 \%)$ & $0(0 \%)$ & $4(1.2 \%)$ & $0(0 \%)$ & $0(0 \%)$ & $0(0 \%)$ & $9(8.6 \%)$ \\
\hline
\end{tabular}

Continuous variables are presented as median [IQR]. Postoperative complications occurring in more than $1.0 \%$ of the study population are shown. ASD, Atrial septal defect; $A V$, atrioventricular.

a high rate of noncardiac/genetic abnormality $(24 \%$ vs $17 \%$ overall) and the highest risk of postoperative heart block requiring a permanent pacemaker $(2.2 \%$ vs $1.3 \%$ overall). The patients undergoing mitral valvuloplasty were predominately female $(72 \%)$ and had a high rate of noncardiac/genetic abnormality ( $27 \%$ vs $17 \%$ overall). These patients also had a high risk of postoperative arrhythmia (16\% vs $9.4 \%$ overall) and a high rate of postoperative pleural effusion ( $8.2 \%$ vs $3.1 \%$ overall). The Ross operation subgroup was relatively young (median, 22 years; IQR, 19-28) and had a low rate of noncardiac/genetic abnormality (6.5\% vs $17 \%$ overall) and other preoperative risk factors ( $14 \%$ vs $31 \%$ overall). The Ross subgroup also had a long CPB time and a high rate of bleeding requiring reoperation ( $8.3 \%$ vs $1.9 \%$ overall). The Fontan revision/conversion cohort was notable for a high rate of any preoperative risk factor, long CPB times, high in-hospital mortality ( $11 \%$ vs $2.1 \%$ overall), relatively longer postoperative length of stay (median, 10 days; IQR, 7-13), and frequent postoperative complications $(51 \%)$.

\section{Society of Thoracic Surgeons Adult Cardiac Surgery Database}

Review of the STS Adult Cardiac Surgery Database revealed 39,872 patients who had undergone ASD repair, pulmonary valve replacement, or other "congenital defect repair" either in isolation or along with coronary artery bypass grafting, aortic valve procedure, or mitral valve procedure. (During the period 2000-2009, cases coded as "congenital defect repair" were not classified with any further granularity in the STS Adult Cardiac Surgery Database.) Table 4 displays the patient characteristics and outcomes associated with these procedures.

\section{DISCUSSION}

This report based on data in the STS Database analyzes the operative outcomes of the growing population of adults with congenital heart disease. The relatively young median age for adults undergoing surgery for congenital heart disease is not surprising. Many operations performed in childhood are palliative and not expected to last a lifetime. Part of the increase in the numbers of young adults with congenital heart disease is accounted for by the fact that survival beyond the first decade or 2 of life is a new phenomenon for some relatively common anomalies, such as hypoplastic left heart syndrome. ${ }^{5}$ However, it should be noted that the patients in our primary analysis included only those entered into the STS Congenital Heart Surgery Database; thus, these data are likely skewed toward younger patients undergoing surgery at congenital heart surgery centers performed by congenital heart surgeons. It has been shown that many adults with CHD undergo surgery at adult centers. ${ }^{17}$ These findings are confirmed in the present analysis in which many more CHD operations were entered into the STS Adult Cardiac Database versus the Congenital Heart Surgery Database. Patients in the adult database were substantially older compared with patients in the congenital database. 
TABLE 4. Society of Thoracic Surgeons Adult Cardiac Surgery Database

\begin{tabular}{lcc}
\hline & ASD repair $(\mathbf{n}=\mathbf{2 6 , 1 1 7})$ & $\begin{array}{c}\text { Congenital defect repair } \\
(\mathbf{n}=\mathbf{1 0 , 1 3 3 )}\end{array}$ \\
\hline Isolated procedure & $9602(37 \%)$ & $2835(28 \%)$ \\
Age $(y)$ & $48[36-59]$ & $44[32-58]$ \\
In-hosplacement $(\mathbf{n}=\mathbf{3 6 2 2})$
\end{tabular}

The overall mortality of $2.1 \%$ for adult patients in the STS Congenital Heart Surgery Database and range of $2.1 \%$ to $5.0 \%$ mortality in the STS Adult Cardiac Surgery Database are within the range of previously published figures of $1.9 \%$ to $4.8 \%$ derived from the Nationwide Inpatient Sample, ${ }^{11}$ an administrative database. Despite $31 \%$ of our overall cohort having at least 1 preoperative risk factor and $28 \%$ experiencing at least 1 postoperative complication, mortality was generally low and length of stay was relatively short in the subgroups analyzed. The length of stay in our study is comparable to the 8 to 10 days described in a previous report from an administrative database. ${ }^{11}$ As this population continues to grow in number over the coming years, with an expected increase in the fraction of patients with complex disease having benefited from newer and more efficacious treatment strategies, continued clinical vigilance will be required to maintain or improve this level of morbidity and mortality.

The highest mortality in our subgroup analysis was found in those undergoing Fontan revision/conversion. Primary Fontan operation early in childhood is associated with low rates of operative mortality, with previous single institution series reporting $1 \%$ to $2 \%$ mortality. ${ }^{18,19}$ The late morbidities associated with the Fontan circulation are now being increasingly recognized. The Pediatric Heart Network Fontan study reported stroke/thrombosis in $8 \%$, seizures in $3 \%$, and protein-losing enteropathy in $4 \%$ of patients undergoing the Fontan procedure approximately 8 years after the procedure. ${ }^{20}$ It is not surprising that patients with declining status who are referred as adults for revision or conversion of the Fontan circulation have numerous comorbidities and are a high-risk surgical group. In the present analysis, we found that Fontan revision/conversion is associated with a mortality rate of $11 \%$. This is higher than that reported by Mavroudis and colleagues ${ }^{21}$ in the largest single institution series published to date. ${ }^{21}$ Differences in the patient populations could account for the differences in mortality between that study and our analysis. Our Fontan revision/conversion cohort had a median age of 27 years, whereas the study by Mavroudis and colleagues analyzed cohorts in 3 eras, with median ages of 16, 19, and 24 years. Our cohort also had noncardiac/ genetic abnormality in $10 \%$, neurologic deficit in $3 \%$, and bleeding disorder in $3 \%$ of patients.

The subgroups undergoing pulmonary valve replacement and ASD repair had few preoperative risk factors and low morbidity and mortality. The mortality for pulmonary valve replacement was lower than that reported in a study from Norway, which included 79 patients aged more than 17 years receiving a pulmonary valve replacement, with overall early mortality of $2.7 \%{ }^{22}$ Shinkawa and colleagues ${ }^{23}$ analyzed 73 patients undergoing pulmonary valve replacement and reported zero perioperative deaths. ${ }^{23}$ Mortality for ASD repair was zero in our study and has been reported to be $0 \%$ to $1.2 \% .^{24,25}$ This is an important observation that should be considered in evaluation of innovative nonsurgical means of accomplishing ASD closure.

The conduit reoperation subgroup was notable for having a high rate of preoperative neurologic deficit $(4.0 \%)$. The cause of this cannot be ascertained from the data available in this study. Our speculation to explain this finding includes a history of undergoing multiple cardiothoracic operations and exposure to multiple episodes of CPB. The mortality for aortic aneurysm repair in this study $(2.2 \%)$ is similar to that in a single institution study from the adult cardiac literature $(2.6 \%){ }^{26}$ Mitral valvuloplasty carried a lower mortality $(0.7 \%)$ than that reported in an Australian congenital study $(4 \%) .{ }^{27}$ However, this single institution Australian study included younger patients (aged 3 days to 21 years), and all 3 mortalities were in patients aged less than 8 years. The Ross operation subgroup had the same mortality $(1.9 \%)$ as a 14-year, single institution study of 160 patients. ${ }^{28}$ The high rate of bleeding requiring reoperation $(8.3 \%)$ in patients undergoing the Ross operation might be explained by the long cardiopulmonary time and the nature of the operation, which includes many suture lines in the high-pressure left ventricular outflow tract.

The results from the STS Adult Cardiac Surgery Database must be interpreted with caution. The category "congenital defect repair" potentially represents a myriad of procedures of varying complexity. There are currently limited data collected regarding the diagnoses, patient characteristics, and details of the procedures performed in the adult database such that detailed analyses are not possible. 
Nonetheless, it is important to consider the overall number of congenital heart surgery operations in the Adult Cardiac Surgery Database, which for the 10-year period represented by these data approaches 40,000 cases. Important modifications to both the STS Congenital Heart Surgery Database, which went into effect in 2010, and the STS Adult Cardiac Surgery Database, which went into effect in 2011, will make more detailed analyses of the entire cohort of adults with CHD undergoing surgery from either database possible. Starting in 2010, the STS Congenital Heart Surgery Database began to collect, on all patients aged 18 years or more, the complete list of patient factors that are pertinent to adult patients; these factors were previously collected only in the STS Adult Cardiac Surgery Database. Starting in 2011, the complete list of congenital cardiac diagnoses and procedures is now shared by both the STS Congenital Heart Surgery Database and the STS Adult Cardiac Surgery Database.

\section{Limitations}

The limitations of this study are primarily related to the nature of the STS Database. Not all US centers participate in the STS Database or submit complete data. Thus, the results of this study may not be generalizable to adults with CHD undergoing surgery at all US centers. In addition, as noted above, our primary analysis focused on patients entered into the STS Congenital Heart Surgery Database. We found there are many more congenital operations captured in the STS Adult Cardiac Surgery Database. As discussed, modifications to the adult database will facilitate future detailed analyses of all CHD operations in adults regardless of which database they are entered into. Finally, the present analysis was primarily descriptive in nature. Detailed information regarding patient preoperative hemodynamic status and other clinical information, in addition to center-level data regarding the presence of a dedicated adult congenital program and surgeon experience with adult congenital procedures, is not currently captured in the database; thus, we were not able to include these factors in the analysis or describe their relationship with outcome.

\section{CONCLUSIONS}

This analysis of adults with CHD in the STS Congenital Heart Surgery Database offers a focused view of this emerging population. The majority of patients undergo surgery in the third and fourth decades of life, and in-hospital mortality is low for most types of procedures. The mortality rate associated with Fontan revision/conversion is higher, which is likely related to important comorbidities that occur in the setting of declining function of the Fontan circulation. For the entire cohort studied, postoperative complications were common, justifying further efforts to characterize and understand risk factors in the adult populations with congenital cardiac disease and processes of care that may reduce overall morbidity. Recent enhancements of the STS Databases should result in the availability of more complete and representative datasets for future analyses. Initiatives to foster collaboration of STS Adult Cardiac and Congenital Heart Surgery Databases with longitudinal registries of adults with CHD may provide the best opportunity to evaluate long-term outcomes in this patient population. $^{29}$

\section{References}

1. Dearani JA, Connolly HM, Martinez R, Fontanet H, Webb GD. Caring for adults with congenital cardiac disease: successes and challenges for 2007 and beyond. Cardiol Young. 2007;17(Suppl 2):87-96.

2. Dearani JA, Mavroudis C, Quintessenza JA, Deal BJ, Backer CL, Fitzgerald P, et al. Surgical advances in the treatment of adults with congenital heart disease. Curr Opin Pediatr. 2009;21:565-72.

3. Warnes CA, Liberthson R, Danielson GK, Dore A, Harris L, Hoffman JI, et al Task force 1: the changing profile of congenital heart disease in adult life J Am Coll Cardiol. 2001;37:1170-5.

4. Hoffman JI, Kaplan S, Liberthson RR. Prevalence of congenital heart disease. Am Heart J. 2004;147:425-39.

5. Azakie T, Merklinger SL, McCrindle BW, Van Arsdell GS, Lee KJ, Benson LN, et al. Evolving strategies and improving outcomes of the modified Norwood procedure: a 10-year single-institution experience. Ann Thorac Surg. 2001;72: 1349-53.

6. Li J, Zhang G, Holtby H, Humpl T, Caldarone CA, Van Arsdell GS, et al. Adverse effects of dopamine on systemic hemodynamic status and oxygen transport in neonates after the Norwood procedure. J Am Coll Cardiol. 2006;48:1859-64. Epub 2006 Oct 17.

7. Nieminen HP, Jokinen EV, Sairanen HI. Causes of late deaths after pediatric cardiac surgery: a population-based study. J Am Coll Cardiol. 2007;50:1263-71. Epub 2007 Sep 10.

8. Bouchardy J, Therrien J, Pilote L, Ionescu-Ittu R, Martucci G, Bottega N, et al Atrial arrhythmias in adults with congenital heart disease. Circulation. 2009;120 1679-86. Epub 2009 Oct 12.

9. Crumb SR, Cook SC, Cheatham JP, Galantowicz M, Feltes TF, Phillips A, et al. Quality outcomes of ACHD patients undergoing cardiovascular procedures and hospital admissions in a free-standing children's hospital. Int J Cardiol. 2011; 146:326-9. Epub 2009 Aug 8.

10. Lamour JM, Kanter KR, Naftel DC, Chrisant MR, Morrow WR, Clemson BS, et al, Cardiac Transplant Registry Database, Pediatric Heart Transplant Study. The effect of age, diagnosis, and previous surgery in children and adults undergoing heart transplantation for congenital heart disease. J Am Coll Cardiol. 2009;54:160-5.

11. Karamlou T, Diggs BS, Person T, Ungerleider RM, Welke KF. National practice patterns for management of adult congenital heart disease: operation by pediatric heart surgeons decreases in-hospital death. Circulation. 2008;118:2345-52. Epub 2008 Nov 7

12. Jacobs ML, Mavroudis C, Jacobs JP, Tchervenkov CI, Pelletier GJ. Report of the 2005 STS Congenital Heart Surgery Practice and Manpower Survey. Ann Thorac Surg. 2006;82:1152-8.

13. Clarke DR, Breen LS, Jacobs ML, Franklin RC, Tobota Z, Maruszewski B, et al. Verification of data in congenital cardiac surgery. Cardiol Young. 2008;18(Suppl 2): $177-87$

14. Johnson JN, Jaggers J, Li S, OBrien SM, Li JS, Jacobs JP, et al. Center variation and outcomes associated with delayed sternal closure following stage 1 palliation for hypoplastic left heart syndrome. J Thorac Cardiovasc Surg. 2010;139: 1205-10.

15. STS Database Full Specifications. Available at: http://www.sts.org/documents/ pdf/Congenital_DataSpecs_250.pdf. Accessed February 1, 2011.

16. O'Brien SM, Clarke DR, Jacobs JP, Jacobs ML, Lacour-Gayet FG, Pizarro C, et al. An empirically based tool for analyzing mortality associated with congenital heart surgery. J Thorac Cardiovasc Surg. 2009;138 1139-53.

17. Karamlou T, Diggs BS, Ungerleider RM, Welke KF. Adults or big kids: what is the ideal clinical environment for management of grown-up patients with congenital heart disease? Ann Thorac Surg. 2010;90:573-9.

18. Ballweg JA, Dominguez TE, Ravishankar C, Gaynor JW, Nicolson SC, Spray TL, et al. A contemporary comparison of the effect of shunt type in 
hypoplastic left heart syndrome on the hemodynamics and outcome at Fontan completion. J Thorac Cardiovasc Surg. 2010;140:537-44.

19. Hasaniya NW, Razzouk AJ, Mulla NF, Larsen RL, Bailey LL. In situ pericardial extracardiac lateral tunnel Fontan operation: fifteen-year experience. $J$ Thorac Cardiovasc Surg. 2010;140:1076-83.

20. Anderson PA, Sleeper LA, Mahony L, Colan SD, Atz AM, Breitbart RE, et al. Contemporary outcomes after the Fontan procedure: a Pediatric Heart Network multicenter study. Pediatric Heart Network Investigators. J Am Coll Cardiol. 2008;52:85-98.

21. Mavroudis C, Deal BJ, Backer CL, Stewart RD, Franklin WH, Tsao S, et al. J. Maxwell Chamberlain Memorial Paper for congenital heart surgery. 111 Fontan conversions with arrhythmia surgery: surgical lessons and outcomes. Ann Thorac Surg. 2007;84:1457-66.

22. Neukamm C, Døhlen G, Lindberg HL, Seem E, Norgård G. Eight years of pulmonary valve replacement with a suggestion of a promising alternative. Scand Cardiovasc J. 2011;45:41-7. Epub 2010 Nov 11.

23. Shinkawa T, Anagnostopoulos PV, Johnson NC, Watanabe N, Sapru A, Azakie A. Performance of bovine pericardial valves in the pulmonary position. Ann Thorac Surg. 2010;90:1295-300.

24. Doll N, Walther T, Falk V, Binner C, Bucerius J, Borger MA, et al. Secundum ASD closure using a right lateral minithoracotomy: five-year experience in 122 patients. Ann Thorac Surg. 2003;75:1527-31.

25. Horvath KA, Burke RP, Collins JJ Jr, Cohn LH. Surgical treatment of adult atrial septal defect: early and long-term results. J Am Coll Cardiol. 1992;20:1156-9.

26. Svensson LG, Deglurkar I, Ung J, Pettersson G, Gillinov AM, D’Agostino RS, et al. Aortic valve repair and root preservation by remodeling, reimplantation, and tailoring: technical aspects and early outcome. J Card Surg. 2007;22:473-9.

27. Oppido G, Davies B, McMullan DM, Cochrane AD, Cheung MM, d'Udekem Y, et al. Surgical treatment of congenital mitral valve disease: midterm results of a repair-oriented policy. J Thorac Cardiovasc Surg. 2008;135:1313-21.

28. Ryan WH, Prince SL, Culica D, Herbert MA. The Ross procedure performed for aortic insufficiency is associated with increased autograft reoperation. Ann Thorac Surg. 2011;91:64-70.

29. Martin GR, Beekman RH, Ing FF, Jenkins KJ, McKay CR, Moore JW, et al. The IMPACT registry: IMproving Pediatric and Adult Congenital Treatments. Semin Thorac Cardiovasc Surg Pediatr Card Surg Annu. 2010;13:20-5.

\section{Discussion}

Dr Joseph Dearani (Rochester, $M d$ ). I have no disclosures. The authorship has provided a well-written article and presentation of a descriptive review of a large number of adult patients with CHD who underwent selected procedures at many institutions. Limitations of this review were acknowledged, and this study exemplifies the strengths and weaknesses of a retrospective review from the STS database.

Strengths include a large patient cohort of more than 5000 adults with CHD, a growing subspecialty with few data present in the literature. Most of the data in this review were from the STS congenital database, and additional data on 3 adult CHD procedures, 2 common ones being pulmonary valve replacement and ASD closure, are from the adult STS database. The assumption is that the majority of procedures in the congenital database were performed by congenital surgeons; however, it is not clear who were the primary operators in the adult database, but it is likely that most were adult surgeons.

The overall early mortality was low at $2 \%$, and not surprisingly it was highest in the single ventricle group at $11 \%$. These findings are consistent with other data in the literature. Postoperative morbidity was common, occurring in approximately one third of the entire group of adults with CHD as you have outlined.

A few findings deserve comment. The early mortality was $2 \%$ for the conduit replacement group, one of the most common procedures performed in CHD, which is higher than many reports in the literature. This may be because the procedure was not an isolated conduit replacement, was related to the underlying congenital diagnosis, or in the presence of multiple prior sternotomies. In the conduit group, $4 \%$ had had a stroke preoperatively, which may have been due to the greater number of prior operations or preexisting cyanosis related to palliation before complete repair in the earlier days of cardiac surgery. The $30 \%$ complication rate is high, particularly with regard to respiratory complications. Conduit replacement is generally viewed as a relatively low-risk, straightforward procedure even in the face of multiple prior operations. Here it stands out as a procedure with significant morbidity and the highest early mortality for all of your groups excluding the Fontan group.

The finding of no early mortality in ASD closure in the congenital database is excellent and sets the gold standard for newer, lessinvasive techniques. However, the ASD repair mortality of $2 \%$ to $5 \%$ in the adult database, depending on whether it was performed in isolation or with other procedures, stands out as high. This may be due in part to improper patient selection or adult surgeons performing congenital operations. The adult STS database also demonstrated a high early mortality of $3.5 \%$ for pulmonary valve replacement. This point deserves emphasis that adult surgeons should not be performing congenital procedures even if it is a "simple ASD closure or pulmonary valve replacement."

I commend you and your coauthors for your efforts to examine a large amount of data and learn more about this difficult and growing patient population, but it is disappointing there is not a single statistical analysis with a $P$ value that was performed with $30+$ variables in 5000+ patients. This highlights one of the weaknesses of the STS database, namely, that it is descriptive with some findings requiring clarification that will go largely unanswered.

I have 3 questions for you.

First, can you clarify why the risk of heart block was highest in the group of patients undergoing ascending aortic surgery?

Second, can you explain the nature of the arrhythmias and the arrhythmia procedures that were performed?

Third, what do you think is the most important new finding from your review that will add to the current literature?

Dr Mascio. To address your first question about heart block in ascending aortic surgery, I really don't have a good explanation for that. It's one of the weaknesses of the database. We know that a certain number of ascending aortic aneurysms were done and that a certain percentage had heart block. Beyond that it's hard to know the specifics of individual cases.

The situation is the same for the arrhythmias. There is simply a box to check whether there is a preoperative arrhythmia or postoperative arrhythmia. On the basis of the data we collected for this study, I cannot comment on the type of arrhythmia or if an intervention, surgical or medical, was done.

As far as the most important new finding, I was impressed with the number of congenital cases done at adult hospitals. I think this puts an exclamation point on something we all know-that these patients are trying to find their home. In other words, some seek care at congenital hospitals. There seems to be no standard formula for their care yet. Although the STS database is not perfect, it does provide a snapshot of what's really going on everywhere.

Dr Rodolfo Neirotti (Cambridge, Mass). I think this is a large and increasing number of patients who deserve some additional 
considerations. One of them is to try to find and adopt a system of risk stratification for them. There is a recent article from Rotterdam in The Netherlands showing that the current pediatric score methods are not helpful unless age is added to the formula.

Are you considering or have you used some sort of risk stratification score? It could be important to determine who these patients are and where they should undergo surgery, particularly those with higher risk.

This group of patients requires a different business model, a different pathway, and a different mindset. And that is applying to them the available knowledge on children's heart diseases in addition to the mindset of adult care. Do you have some inference and recommendations regarding this potential business model, pathway, and mindset for this particular group of patients?

Dr Mascio. To address your first question, I think the next step should be to start looking at risk stratification. Now that we have an idea of how many adult patients have complications and what the overall survival is, it is time to see if we can link pre- or postoperative factors to mortality.

To address your second question as far as business model and mindset, I would say that complex patients with adult CHD belong in children's hospitals or hospitals that take CHD cases. There have been publications that have indicated a lower in-hospital mor- tality rate for adults with CHD when they undergo operation by pediatric heart surgeons and they're cared for in CHD centers. That's my mindset, and I think that's what the business model needs to be. Admitting a Fontan case to a unit that takes care of coronary bypass graft cases is not a good plan.

Dr Tara Karamlou (Seattle, Wash). I just wanted to make one point and then ask one question. I applaud your use of this new database, because our group has reached similar conclusions using the Nationwide Inpatient Sample. However, just to emphasize, I think this current data set is probably not, at least right now and maybe not for many years, a good one to look at this population, because from our own literature most of these patients aren't cared for in tertiary care settings. I would hypothesize that the participants of the congenital database in particular are probably not the centers where most of these patients are receiving care.

You alluded to and it's probably a surrogate for whether it's a pediatric heart surgeon or an adult-acquired surgeon doing the cases. Is there a way or do you plan to look at surgeon factors? Because I think that would be a good use of this data set.

Dr Mascio. We were not able to sort out what type of surgeon performed the operation and at what type of hospital, but it should be a part of future studies using the database. 